Revista da Rede Brasileira de História da Geografia e Geografia Histórica

$11 \mid 2019$

Mapas e mapeamentos: conhecer, apresentar e agir

\title{
Destinos en movimiento
}

Reflexiones en torno al turismo y la movilidad en la Quebrada de Humahuaca (Argentina)

Destinos em movimento: Reflexões sobre o turismo e a mobilidade na Quebrada de Humahuaca (Argentina)

Destinations in motion: Considerations on tourism and mobility at Quebrada de Humahuaca (Argentina)

Destinations en mouvement : Réflexions à propos du tourisme et de la mobilité à la Quebrada de Humahuaca (Argentina)

\section{Claudia Alejandra Troncoso}

\section{(2) OpenEdition}

\section{Journals}

Edición electrónica

URL: https://journals.openedition.org/terrabrasilis/3805

DOI: $10.4000 /$ terrabrasilis.3805

ISSN: 2316-7793

Editor

Rede Brasileira de História da Geografia e Geografia Histórica

Referencia electrónica

Claudia Alejandra Troncoso, «Destinos en movimiento», Terra Brasilis [En línea], 11 | 2019, Publicado el 31 agosto 2019, consultado el 05 diciembre 2022. URL: http://journals.openedition.org/terrabrasilis/ 3805 ; DOI: https://doi.org/10.4000/terrabrasilis.3805

Este documento fue generado automáticamente el 5 diciembre 2022.

All rights reserved 


\title{
Destinos en movimiento
}

\author{
Reflexiones en torno al turismo y la movilidad en la Quebrada de \\ Humahuaca (Argentina)
}

Destinos em movimento: Reflexões sobre o turismo e a mobilidade na Quebrada

de Humahuaca (Argentina)

Destinations in motion: Considerations on tourism and mobility at Quebrada de

Humahuaca (Argentina)

Destinations en mouvement : Réflexions à propos du tourisme et de la mobilité à

la Quebrada de Humahuaca (Argentina)

Claudia Alejandra Troncoso

1 Turismo y movimiento están estrechamente relacionados. Las diversas, y en ocasiones contrastantes, formas de definir el turismo comparten como punto de partida (prácticamente consensuado) ${ }^{1}$ la idea de que el desplazamiento espacial es necesario para hablar de turismo.

2 Las aproximaciones más empiristas y estadísticas que abordan la movilidad o el desplazamiento en el turismo parten de ofrecer cifras que dan cuenta de él como fenómeno global de desplazamiento y que expresan qué tan móvil nos hemos vuelto cuando se trata de ocio. Este tipo de información incluye datos (predominantemente numéricos) que muestran cuántos turistas se desplazan, desde dónde, hacia dónde, por cuánto tiempo, con quién, gastando cuánto $\mathrm{y}$, como suele priorizarse en el turismo, cuál es la traducción económica de todo esto. ${ }^{2}$

3 Con menos frecuencia se ha abordado el estudio de otros aspectos de este desplazarse con fines de ocio que ha devenido una práctica distintiva de los tiempos modernos, al menos en las sociedades occidentales. ¿Cómo es este “estar en movimiento” para el turista? ¿En qué consiste este ir de un lugar a otro, del lugar de residencia al lugar de visita?, ¿Cómo es moverse entre varios lugares de visita que componen el viaje turístico? ¿Cómo se transitan estos desplazamientos? ¿El desplazamiento turístico es simple traslado? ¿O es algo más? ¿Qué más? ¿Cómo vivimos nuestros tiempos (y espacios) de desplazamiento? Podemos pensar en dos situaciones bien diferentes: desde 
el viaje vivido como simple traslado, como tiempo indispensable para cubrir distancias, plagado, muchas veces, de incomodidades largamente subrayadas (que llevan al tedio, al aburrimiento, a la irritabilidad), hasta las propuestas donde el desplazarse "lo es todo" como la invitación que ofrecen los cruceros o aquellos míticos servicios ferroviarios donde importa más cómo se pasa el tiempo a bordo conectando destinos (haciendo qué, con quién, bajo qué propuesta temática), que el tiempo en los destinos mismos.

Entre estos extremos, varios han sido los temas específicos que convocaron la atención de los estudiosos de los viajes turísticos que pusieron atención en los desplazamientos de los turistas: viajes en tours organizados (Edensor y Holloway, 2008), recorridos a pie (Toniol, 2011), recorridos en bus turístico (Farías, 2010), experiencia de tránsito por rutas turísticas (Zillinger, 2007), etc. En especial las discusiones sobre la movilidad, potenciadas en los últimos tiempos con el surgimiento en el mundo académico del new mobilities paradigm, ${ }^{3}$ han procurado ofrecer elementos para reflexionar acerca de estas experiencias e indagar en su densidad y su riqueza. Entre otras cosas, estas perspectivas han intentado comprender los desplazamientos turísticos presentados a la luz de reflexiones y análisis que abrevaron en diversas propuestas conceptuales que no dan por supuesto, por ejemplo, que el tiempo de traslado es un "tiempo muerto" en el que nada sucede (Cresswell, 2010). ${ }^{4}$

5 Todas estas contribuciones, de manera más o menos explícita, buscaron abordar una geografía del turismo que se alejara del énfasis predominante en los estudios que ponen atención exclusivamente en los destinos y los atractivos, es decir, en los lugares turísticos y las transformaciones que los definen. ${ }^{5}$ Por el contrario, problematizaron la idea de que el viaje es un medio para llegar a determinados lugares/objetos/experiencias de interés turístico poniendo en evidencia la riqueza de las distintas formas de desplazamiento implicadas en el turismo. Desde este punto de partida se ha avanzado en conocer el movimiento que los turistas realizan, por ejemplo, al desplazarse por una ciudad, así como los recorridos que enlazan varios destinos (a modo de ruta o circuito turístico). El movimiento, la movilidad, el desplazamiento se vuelven centro de indagaciones de estos espacios de transición - los espacios del desplazamiento - que en la academia, como en la promoción turística, muchas veces han sido pasados por alto (Franklin y Crang, 2001: 12). Poner el foco en el movimiento no implica centrar la atención en los recorridos "desde y hasta" sino pensar el movimiento como un elemento constitutivo del turismo - y de todo el territorio turístico en los términos que propone Bertoncello (2002) - es decir, de lugar de origen y de lugar de destino incluidos. Esto implica, entre otras cosas, pensar que los destinos turísticos no son los lugares de llegada, donde el desplazamiento, el traslado y el movimiento terminan. Por el contrario, supone asumir los destinos turísticos también marcados y constituidos por el movimiento. Y esto, en última instancia evitaría el tratamiento de los lugares turísticos como lugares estáticos, condenados a la inmovilidad y en última instancia cerrados en sí mismos (Crang, 2006).

6 Entonces, ¿cómo se experimentan y se transitan los espacios del movimiento en un viaje turístico? ¿Cómo se organizan estos espacios de la mano de este movimiento? ¿Cómo varían con el tiempo a partir de cambios en la movilidad o cómo se transforma la movilidad en ellos a partir de los propios cambios que caracterizan a los lugares? Y más aún, ¿qué aspectos nuevos puede develar el estudio del turista en movimiento para comprender los lugares del turismo? 
Interesa abordar estas preguntas vinculadas a un destino turístico, la Quebrada de Humahuaca. Este valle en el noroeste de la Argentina (provincia de Jujuy) (ver figura 1), próximo a los límites internacionales con Bolivia y Chile, ha devenido en las últimas décadas uno de los destinos más visitados del país. Lo conforman un grupo de localidades dispuestas en el valle del río Grande y algunos de sus afluentes que suelen visitarse de manera conjunta durante un viaje turístico. El trabajo pone atención en algunos aspectos vinculados a la transformación del lugar que incluyen aquellos relacionados con la manera en que se transita el destino. Estos aspectos hacen del análisis de este caso un punto de partida para poner en discusión algunas cuestiones en torno al movimiento turístico.

8 La información acerca del turismo en este destino, y especialmente las formas que toma el desplazamiento en él, surge a partir de la consulta de una serie de documentos históricos que presentan las formas de transitar este valle (artículos científicos, memorias, documentos biográficos, etc.), observaciones de la dinámica de desplazamiento de los turistas en las diferentes localidades turísticas de la Quebrada, participación en tours organizados y excursiones realizadas en vehículos particulares acompañando turistas, y entrevistas realizadas a guías turísticos. También se consultaron diferentes materiales de promoción turística que también orientan o sugieren formas de recorrer el destino (guías turísticas, folletos turísticos, etc.). Asimismo, de manera complementaria, se recogieron testimonios de turistas disponibles en sitios web.

Figura 1. Quebrada de Humahuaca en el noroeste argentino

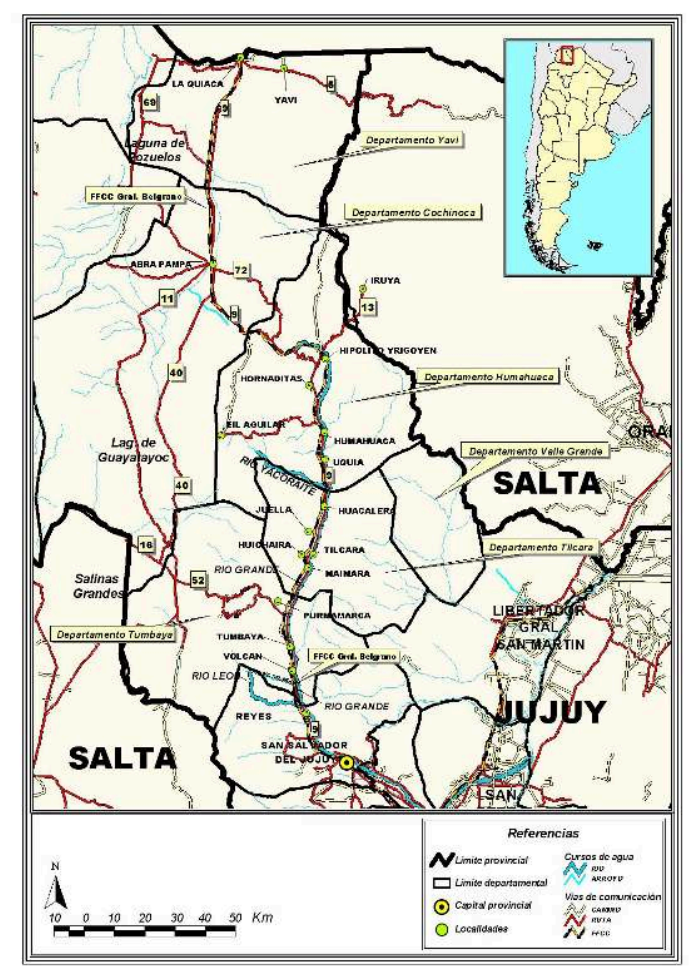

Elaboración: Lucas Ramírez 


\section{La Quebrada de Humahuaca y el turismo en la historia}

9 A comienzos del siglo XX, en pleno desarrollo del turismo de elite en la Argentina, el valle norteño conocido como Quebrada de Humahuaca constituía un destino de descanso estival para las familias adineradas de las capitales del noroeste del país (San Salvador de Jujuy, Salta, San Miguel de Tucumán). Estos visitantes asiduos habían construido casas de veraneo en algunas de sus localidades para pasar los meses estivales a resguardo del calor y lejos de enfermedades propias de climas húmedos donde residían (por ejemplo, el paludismo) (Seca, 1989). Estos desplazamientos, realizados hasta ese momento en coches tirados por caballos que acompañaban el discurrir del río Grande (curso de agua principal que recorre este valle), fueron facilitados por la llegada de un ramal del ferrocarril General Belgrano (en aquel entonces Ferrocarril Central Norte) a Humahuaca en 1906 proveniente de San Salvador de Jujuy. La traza de este ramal también acompañaba el recorrido del río Grande en su amplio lecho cercado por las laderas escarpadas que identifican a la Quebrada como un valle encajonado.

10 Hacia 1920 la llegada de los veraneantes se hacía evidente en algunas localidades. En Tilcara, por ejemplo, estas visitas duplicaban su población residente durante el verano. Para ese entonces, tanto Tilcara como Maimará (localidad creada en torno a la estación del ferrocarril del mismo nombre) alojaban a estos visitantes no solo en casas de veraneo sino en una incipiente oferta turística que incluía algunos pequeños hoteles y pensiones (Seca, 1989). A esta oferta se agregaría el Hotel Monterrey, inaugurado en 1948 en la localidad de Huacalera (Suárez Giambra, 2007).

11 Poco a poco, y acompañando el afianzamiento del turismo masivo en la Argentina, la Quebrada fue consolidándose como uno de los destinos más importantes del noroeste argentino para turistas provenientes de todo el país. La llegada al lugar a través del ferrocarril fue complementada con el trazado de la ruta nacional №9 en la década de 1940. Como en el caso del ferrocarril, ella conecta también los distintos pueblos que se disponen a lo largo del valle. Su construcción fue acompañada de la instalación de la estación de servicio del Automóvil Club Argentino en Humahuaca, localidad más poblada del valle, en 1942 (Ballent, 2005). Transporte ferroviario y transporte automotor fueron las dos formas de acceso predominante a la Quebrada hasta comienzos de la década de 1990 cuando, como parte del proceso de privatización de los ferrocarriles en la Argentina, el ramal del ferrocarril Belgrano que recorría la Quebrada suspende su funcionamiento. A partir de ese momento, las localidades quebradeñas visitadas por los turistas serán hilvanadas de manera casi exclusiva por el trazado de la ruta №9 y otras vías de circulación secundarias. Por ellas transitarán los turistas que se detienen en las localidades para recorrer los pueblos, alojarse, comer, visitar museos, etc.

12 Las opciones de llegada de turistas a la provincia de Jujuy cambian en 1967 cuando se inaugura el aeropuerto internacional El Cadillal en Perico, cerca de la ciudad capital, San Salvador de Jujuy. Sin embargo, la llegada a la Quebrada (desde la localidad de San Salvador de Jujuy o de otras localidades del noroeste a las que se puede llegar en avión) se podrá realizar solo con transporte ferroviario y automotor. Para este momento también la hotelería muestra un crecimiento en la Quebrada, especialmente en las localidades de Tilcara y Humahuaca. Durante las décadas de 1970 y 1980 se terminarán de definir las características turísticas de la Quebrada que prevalecen hasta mediados 
de la década de 1990: visitas durante el verano de veraneantes con casa propia y visitas turísticas que aprovecharán los servicios de los hoteles provinciales en las localidades de Tilcara y Humahuaca ${ }^{6}$ o algunos otros servicios de alojamiento y gastronomía que componen una oferta limitada. Para este momento se consolida una forma de visitar la Quebrada a través de viajes en el día que parten desde las ciudades de San Miguel de Tucumán, Salta y San Salvador de Jujuy donde se localizan agencias de viaje que ofrecen estos tours hacia las localidades quebradeñas. Esto explica el escaso desarrollo de sector hotelero; sí se desarrollará en cambio, especialmente en Humahuaca, el sector gastronómico destinado a brindar servicios de restauración a los grupos de turistas que llegan al mediodía con los tours.

13 La pavimentación de la ruta nacional №9 en la década de 1970 (en el tramo San Salvador de Jujuy hasta Humahuaca) favorecerá el desplazamiento a través de la Quebrada, y también consolidará la vista en el día como modalidad turística predominante (Troncoso, 2012).

14 La Quebrada tiene una historia de vía de circulación previa a la llegada del turismo (aunque no era el único camino que organizaba el desplazamiento en esta zona del noroeste), pero las formas de circulación modernas a través del ferrocarril y el transporte automotor (que el turismo aprovecha) tendieron a concentrarse en el valle, acompañando el recorrido del río. El turismo, como en otros destinos, se ha sumado a formas de utilización de recorridos, infraestructuras, vehículos y servicios empleados para otros fines. Así, su presencia en la Quebrada no hace más que insistir en sentidos y direcciones de desplazamiento históricamente consolidados a través del comercio y otras prácticas de movilidad locales y regionales como las migraciones y los desplazamientos cotidianos. ${ }^{7}$

Hacia fines de la década de 1990 comenzaría lentamente un período de crecimiento del turismo que coincidirá con el reconocimiento de la Quebrada de Humahuaca como Patrimonio Mundial por la UNESCO (2003). Este crecimiento (expresado en el aumento de visitantes y de servicios turísticos) acompaña las tendencias nacionales de incremento del turismo en la Argentina. El proceso se dio, además, de la mano de la apuesta al turismo como una actividad clave en la Argentina a partir de la década de $2000 .{ }^{8}$ En la actualidad la oferta turística de alojamiento, gastronomía y servicios complementarios se concentra especialmente en las tradicionales localidades de Tilcara y Humahuaca, a las que se agregó Purmamarca, la cual se posicionó como localidad turística con un crecimiento notable en las dos últimas décadas (Troncoso, 2012). Para este momento también se afianza una forma de viajar ya tradicional para los turistas argentinos, especialmente los jóvenes: el viaje al norte de la Argentina, pasando por la Quebrada de Humahuaca, hasta la frontera con Bolivia y más allá, en un viaje (frecuentemente de bajo presupuesto) que buscar conocer los países andinos.

La visita a la Quebrada mediante excursiones en el día sigue vigente, pero progresivamente las localidades quebradeñas se transformaron en lugares de estadía donde la permanencia se prolonga (esto es en parte facilitado por el crecimiento de la oferta de alojamiento y gastronomía). ${ }^{9}$ Incluso, desde ellas los turistas parten para recorrer distintos puntos a lo largo del valle y zonas vecinas. Entre las excursiones que se han promovido como visitas obligadas en las últimas décadas está el viaje a Iruya (desde Humahuaca o desde Tilcara) y a las Salinas Grandes (principalmente desde Purmamarca). Estas excursiones han sido facilitadas por transformaciones en la infraestructura y los servicios. El intenso tránsito hacia Iruya ha sido posibilitado por 
un aumento espectacular en los servicios de transporte automotor hacia esa localidad (hacia mediados de la década de 1990 partían desde Humahuaca dos micros por semana; hoy parten de Humahuaca y Tilcara varios servicios por día). Las Salinas Grandes se han vuelto más accesibles para el turismo a partir de la pavimentación en 2005 de la ruta nacional $\mathrm{N}^{\circ} 52$ que conecta la $\mathrm{RN}^{\circ} 9$ con el paso internacional de Jama en la frontera argentina con Chile. ${ }^{10}$

Los cambios en los servicios de transporte y las transformaciones en la infraestructura claramente han orientado las formas de desplazamiento turístico en la Quebrada marcando hacia dónde, con qué frecuencia, a través de qué medios los turistas llegan y recorren este valle. La velocidad y el ritmo del viaje han cambiado según se considere el tren o el transporte automotor, así como también varía si se utilizan servicios de ómnibus de larga distancia, locales o vehículos propios. Pero la movilidad turística también ha estado condicionada por estas otras dinámicas que definieron a este destino: básicamente el crecimiento y localización de los servicios turísticos. La Quebrada pasó de ser un lugar visitado en el día en una de las clásicas excursiones comentadas que pueden ser contratadas en las ciudades de Salta o San Salvador de Jujuy a constituir un lugar de estadía y centro de excursiones hacia aquellos puntos de interés turístico que incluye algunos poco frecuentados hasta hace unos años. En definitiva, este lugar se redefine en tanto destino turístico y redefine su relación con otros destinos de la región, en la medida en que las localidades quebradeñas devienen lugares de estadía turística con una mayor presencia de turistas en ellas (Troncoso, 2012).

\section{La Quebrada y sus visitantes en movimiento}

Más allá de medios de transporte, servicios e infraestructura, ¿qué aspectos caracterizan el adentrarse y recorrer este valle? ¿Cómo es este transitar por la Quebrada? ¿Cómo se ha hecho históricamente?

Existen relatos y descripciones históricas de visitantes a la Quebrada que permiten recuperar las formas pasadas de recorrer este lugar. Varios escritores, artistas, académicos que han transitado y residido en la Quebrada elaboraron escritos en los que describen esta llegada a la Quebrada. ${ }^{11}$ Una de las cuestiones que llama más la atención al observar estos textos es la manera en que se han consolidado ciertas formas de apreciar la llegada al lugar marcadas, especialmente, por la observación del paisaje.

En efecto, una de las formas en que históricamente se ha presentado la Quebrada y algunas de sus particularidades devenidas atractivos es a través de descripciones que recrean el tránsito a lo largo del valle desde la ciudad de San Salvador de Jujuy hacia el norte. En estas formas de presentar el lugar el énfasis está puesto en la sucesión de aspectos cambiantes relacionados con las variaciones en altura del terreno y la vegetación conforme se avanza hacia el norte (al desplazarse en ese sentido la altura del terreno aumenta y la temperatura, la humedad - y eventualmente la nubosidad disminuyen). La vegetación progresivamente pierde exuberancia a la vez que el suelo se muestra con más frecuencia desnudo. En efecto, la escasa vegetación al norte de la localidad Volcán (donde las condiciones de aridez se acentúan) deja al descubierto la roca de las laderas montañosas, dando paso a la variedad de sus colores que contrastan con el verde de la vegetación predominante al sur generando lo que con frecuencia se destaca como un "brusco y admirable cambio del paisaje montañoso" (Nagel, 1934: 543). 
Aquí, en palabras de dos asiduos visitantes de la Quebrada, ${ }^{12}$ un ejemplo de cómo solía describirse este viaje en las primeras décadas de la circulación del ferrocarril:

Saliendo de Jujuy con rumbo al norte, la quebrada se presenta en toda su amplitud; las montañas no son muy elevadas y sus pendientes suaves están cubiertas de verde follaje hasta sus cumbres. Luego, las sierras van estrechándose, la pendiente se hace más áspera, la vegetación disminuye y aparecen los cardones, primero como atalayas aislados, luego como batallones de soldados rígidos que, arma al brazo, sólo esperan la voz del jefe para arrojarse sobre el invasor. Al final de la jornada la Quebrada de Humahuaca se torna triste, la vegetación tiende a desaparecer y hasta los cardones disminuyen como sabiendo que esos altos lugares ya no necesitan guardianes (Casanova, 1936, citado en Sánchez de Bustamante, 1937: 14).

[Al norte de Volcán] el paisaje que nos rodea es aún más estupendo que lo que ya hemos visto. En este suelo la naturaleza ha volcado a manos llenas lo más valioso de su bagaje estético. (Armanini, 1935: 86)

21 Además de la idea de gradiente que está presente en las descripciones, el tránsito por la Quebrada se presenta como una invitación a observar una sucesión de colores y formas inusuales. La sorpresa y el asombro del viajero se suceden y renuevan en cada tramo de este viaje. El paisaje no da respiro y la observación parece ser una actividad constante. Así, se señala que: "Riel arriba - pues trepa cerca de tres mil metros - la ventanilla del tren renueva sin cesar la visión de los soberbios panoramas jujeños” (Vega, 1934: 303) signados por "cerros de mil caprichosas formas y de múltiples colores" (Montagne, 1944: 62) y "montañas de ensueño; montañas de ilustraciones en color para cuentos de niños" (Vega, 1934: 304).

Más allá de los elementos de la topografía marcados por el gradiente de altura sobre el nivel del mar, la vegetación, la temperatura y la nubosidad, también se destacan otros aspectos de los pueblos quebradeños y la cotidianidad del lugar. Así lo describe Ernesto Soto Avendaño: ${ }^{13}$

Pasan cardones, blancos enterratorios, viejos antigales, minúsculos pueblecillos, algunos coyas enfundados en sus ponchos y tocados con grandes sombreros ovejunos, una mujer con su guagua, un chango guiando sus burritos. (Soto Avendaño, 1930:19)

El trazado de la línea del ferrocarril a lo largo del valle explica la profusión de estas descripciones en movimiento. En efecto, muchas de ellas recrean el tránsito que quienes escriben realizaron para llegar a las localidades quebradeñas; son descripciones "lineales" (Wyckoff y Dislaver, 1997), espacialmente hablando, que se ajustan al recorrido del ferrocarril y que insisten en un área de esta zona de la provincia de Jujuy, aquella visible desde el espacio acondicionado para el tránsito. Asimismo, estas descripciones se realizan siguiendo el sentido sur-norte que es la que toman la mayoría de los viajeros que desde distintos puntos del país llegan a la Quebrada. ${ }^{14}$ Lo que se describe es la primera impresión que se tiene del lugar (raramente se describe el viaje de regreso que atraviesa el valle en el sentido opuesto).

Pero aquello que se ve desde el tren no es lo único que llama la atención a los viajeros; el mismo medio de transporte, y sus aspectos técnicos, constituyen motivos de asombro. El aspecto más destacado en este sentido, y que se repite una y otra vez en los textos, es el ascenso con cremallera y las locomotoras de adherencia en un tramo al sur de Volcán donde la pendiente es más pronunciada:

Una máquina poderosa y chata resopla prendiéndose de las vías con fragor. En la empinada cuesta arriba parece, a ratos que se le acaba el aliento. Apenas consigue 
arrastrar el convoy. La idea de un maquinista heroico se despereza y agiganta. Subimos. (Vega, 1934: 304)

Valiéndose de un dispositivo especial, la locomotora empuja la hilera de coches en un penoso esfuerzo y constante jadeo. La pendiente es muy pronunciada. (Armanini, 1935; 85)

\section{él: la proeza técnica adaptada a una topografía desafiante de la cual el turista es testigo. La observación no se dirige sólo a aquello "que se ve desde la ventanilla" sino al propio movimiento (esforzado, dificultado, friccionado) por aquel lugar.}

Este relato de la llegada a la Quebrada de la mano del ferrocarril se extenderá a otras formas de transitar el valle. Así, también hay invitaciones a leer este desplazamiento de manera similar para aquellos que realizan el viaje en automóvil. Un ejemplo se encuentra en una guía turística impresa por YPF en 1998:

Poco después de pasar la localidad de León, en el $\mathrm{km} 26$ comienza un pequeño tramo de ripio sobre la ladera oriente de la quebrada, a una altura que evita las crecientes del río Grande. En este punto del recorrido ya se ha definido la estructura del paisaje: desaparece el horizonte distante, reemplazado por dos cadenas de montañas de más de $3.000 \mathrm{~m}$, abruptas, de colores cambiantes y en partes cubiertas por vegetación. El camino corre por el fondo del angosto valle, junto al trazado del ferrocarril y el ancho cauce de río Grande. [...] Desde aquí [Volcán] comienza el área media de la quebrada, notablemente diferente a la zona entre la ciudad de Jujuy y León. [...] La espesa vegetación del bosque subtropical, que río abajo cubre las faldas de los cerros, es substituida por cactáceas y arbustos aislados que apenas salpican las montañas ahora desnudas y fuertemente coloreadas en verdes, ocres y rojos. (YPF, 1998: 263-264)

De esta manera, las formas de describir el tránsito por la Quebrada de Humahuaca marcando la sucesión de aspectos cambiantes del lugar y de atractivos específicos de sur a norte siguieron vigentes en el tiempo. En efecto, este relato se recrea en las excursiones a la Quebrada: quienes guían la visita en los tours organizados que se desplazan por la ruta $\mathrm{N}^{\circ} 9$ reproducen en gran medida este relato que va dando cuenta de estas transformaciones conforme se avanza hacia el norte. Pero por sobre todo, el viaje por la ruta $\mathrm{N}^{\circ} 9$ continúa siendo presentado como una sucesión de vistas paisajísticas donde priman las referencias a las formas y los colores (cambiantes, llamativos, inusuales) que presentan las laderas del río Grande, en combinación con algún aspecto de la vida cotidiana de la población local. Las vistas a lo largo de la ruta continúan siendo descritas en las guías turísticas de esta manera:

El marco natural es siempre estupendo y variado en alturas, formaciones y colores.

(YPF, 1998: 263)

Los cerros multicolores, que siempre están presentes a lo largo del recorrido de la quebrada, realmente se destacan porque adquieren tonalidades especiales, en particular a la altura del pueblo de Maimará. (YPF-ACA, 2005: 34)

Recorriendo la Quebrada, se transita por pequeños pueblos donde se mantienen vivas las culturas y tradiciones ancestrales. Calles de piedra, casas de adobe, techos de torta de barro y antiguas iglesias de la conquista española, son el medio cultural donde se desenvuelve la vida de pobladores descendientes de aguerridas tribus nativas y soldados de la guerra por la independencia. (Pueblos Andinos, 2001: 4)

En el caso de la Quebrada de Humahuaca, el valle del río Grande, orientador del desplazamiento predominante, ha albergado tanto al trazado del ferrocarril como de la ruta nacional $\mathrm{N}^{\circ} 9$ en lo que podríamos considerar un recorrido panorámico, es decir, un "dispositivo para ver y experimentar el paisaje" (Hvattum, Brenna, Elvebakk y Larsen, 2011: 1), actividad tan cara al viaje turístico. En efecto, hay un llamado de 
atención, una invitación por parte de quienes realizaron el viaje, a transitar ese valle observando este paisaje cambiante mientras se está en movimiento. El tiempo de tránsito es un tiempo de admiración, reflexión, comparación fundamentalmente acerca de lo que se observa. Claramente, no se trata de un tiempo muerto.

Las apreciaciones acerca de propia infraestructura de transporte seguirán también vigentes, especialmente signadas por el asombro ante la proeza de desafiar las condiciones del terreno. Ahora ya no serán las respuestas técnicas del ferrocarril sino la destreza del vehículo automotor para encarar ascensos pronunciados, tramos de cornisas, interminables curvas y escasos puestos de provisión de combustible. Ejemplos de esto son el recorrido sinuoso de la ruta nacional $\mathrm{N}^{\circ} 9$ cerca de Bárcena (justamente el tramo de mayor pendiente de la Quebrada) y la traza de la ruta nacional $\mathrm{N}^{\circ} 52$ en la Cuesta del Lipán. Las vistas en altura del trazado de esta última, además, merecen paradas ineludibles en puntos panorámicos para tomar fotografías para aquellos turistas que toman esta ruta en su camino a Salinas Grandes.

En términos turísticos, la presencia del tren y la posterior llegada de los vehículos automotores desplazándose por la Quebrada habilitaron diferentes formas de uso y disfrute de este valle: desde aquellas de orden práctico vinculadas al tránsito (más rápido, más seguro, más independiente, según el caso) hasta otras vinculadas con la apreciación estética. En ambos casos, se ponen a disposición del viajero turista nuevas formas de apreciación de un lugar que en diferentes momentos y por diferentes motivos ha sido calificado como contrastante, distante $\mathrm{u}$ opuesto a los ámbitos cotidianos de los turistas. ${ }^{15}$

31 La dirección de los desplazamientos por la Quebrada también es guiada por la información que compone la señalética vial que indica cómo y hacia dónde debe dirigirse el turista para llegar a determinado lugar o encontrar determinado servicio. Pero esto además también se encuentra sugerido por guías turísticos, guías de viaje, folletos promocionales, entre otros. El énfasis en las actividades de observación y registro fotográfico y fílmico fue consolidando determinados puntos de observación y recorridos desde los cuales pueden apreciarse ciertas vistas ya emblemáticas de la Quebrada. Aquí algunos ejemplos dictados por guías turísticas, donde no sólo se sugiere la pausa para la fotografía sino también el momento del día para hacerlo:

El conjunto de cerros conocido como la Paleta del Pintor es ideal para tomar fotografías. (Clarín-ACA, 2010: 22)

(...) para apreciar este paisaje lleno de colores [la Paleta del Pintor] en todo su esplendor, conviene esperar hasta la tarde. La mejor luz, para sacar fotografías también aparece después del mediodía. (Clarín, 1991-1992 aprox.: 2)

Su mejor hora para observarlo [al Cerro de los siete colores] es desde cuando comienza a salir el sol hasta el mediodía, cuando el sol refleja en la montaña la luz adecuada para que ninguno de los pigmentos pase desapercibido para el ojo humano. (Welcome Argentina, 2018) ${ }^{16}$

Esto lo retoman los propios turistas en sus comentarios en los sitios de información turística que lo permiten. Acerca de la visita a Purmamarca una turista cuenta su experiencia:

Fui dos días seguidos. El primer día ni bien llegamos por la tarde a eso de las $16 \mathrm{hs}$. No se aprecian los colores. Al otro día fuimos a las 10 de la mañana y es otra cosa. La luz solar es muy importante. Los mejores lugares para sacar fotos son la esquina de la plaza en donde está el algarrobo y sobre la ruta pasando el parador de las combis de turismo por donde está el hotel Colores, unas cuadras antes. (Tripadvisor, 2018) ${ }^{17}$ 
La ruta $\mathrm{N}^{\circ} 9$ organiza una visita lineal a la Quebrada, marcada por el intenso desplazamiento de turistas entre las localidades quebradeñas. Ella es el eje central actual del desplazamiento en este destino pero además es el recorrido desde el cual se contemplan muchos de los atractivos que la Quebrada ofrece: las formaciones geológicas y geomorfológicas que flanquean la ruta, los pueblos de la Quebrada, el monolito que marca la línea del Trópico de Capricornio, la cartelería que celebra la condición de Patrimonio Mundial del lugar, etc. Pero también hay otros recorridos y puntos de observación consolidados en décadas de visitas turísticas: entre ellos, el Pucará de Tilcara y el camino ascendente a la Garganta del Diablo desde Tilcara que permiten tener una visión panorámica del fondo de valle del río Grande; el Monumento de la Independencia desde donde se observa la ciudad de Humahuaca; el mirador ubicado a la entrada de Maimará que permite apreciar desde un único punto de observación la formación geológica conocida como la Paleta del Pintor junto con el colorido cementerio en altura de la localidad; y el cerro Porito en la localidad de Purmamarca desde donde se obtiene una vista cercana del cerro de los Siete Colores. Todos ellos son también punto de toma de fotografías y grabación de videos. Acondicionamientos turísticos y patrimoniales (cartelería, centros de interpretación del paisaje) e imágenes ampliamente difundidas por la publicidad turística invitan a detenerse, observar, fotografiar o filmar en puntos específicos de los recorridos por la Quebrada (Troncoso, 2013).

Esta forma que toma la visita o el recorrido se organiza espacial y temporalmente: los turistas se detienen en los lugares desde donde se obtienen vistas, se toman fotos y compran souvenirs y aceleran el paso en el resto de los trayectos. En efecto, en los viajes con tours organizados estos trayectos entre lugares de parada se aprovecharán para señalar algún atractivo puntual, para incluir alguna explicación general acerca del destino recorrido o, simplemente, este tiempo será musicalizado con piezas representativas del folklore local en un intento por ofrecer algún tipo de información adicional acerca del destino.

Las transformaciones en la Quebrada que se generaron de la mano del crecimiento del turismo también trajeron la consolidación de nuevos recorridos y puntos panorámicos. En la localidad de Purmamarca uno de ellos, ubicado a la entrada del pueblo desde donde por primera vez se divisa el Cerro de los Siete Colores, se ha convertido en una parada obligada de los vehículos de tours organizados y de los turistas que se desplazan por su cuenta para obtener la fotografía clásica del cerro (ver figura 2). También se ha constituido en un sitio al cual los lugareños se acercan para vender artesanías y souvenirs y el lugar donde se emplazó cartelería oficial con la intención de describir el cerro en sus aspectos geológicos. Este punto de parada se vuelve mucho más concurrido por la mañana y hasta el mediodía, momento con la iluminación ideal para obtener la foto del Cerro de los Siete Colores (como explicaba la turista de la cita más arriba). Esto lo saben los tours organizados que programan las excursiones para detenerse en la localidad en este momento del día. Momentos y lugares de observación, toma de fotografías, filmación y eventualmente compra de souvenir son creados y reforzados por los tours organizados que han definido sus recorridos en función de estos puntos de parada en los que convergen también los residentes para ofrecer diversos productos. 
Figura 2. Punto de observación del Cerro de los Siete Colores, Purmamarca

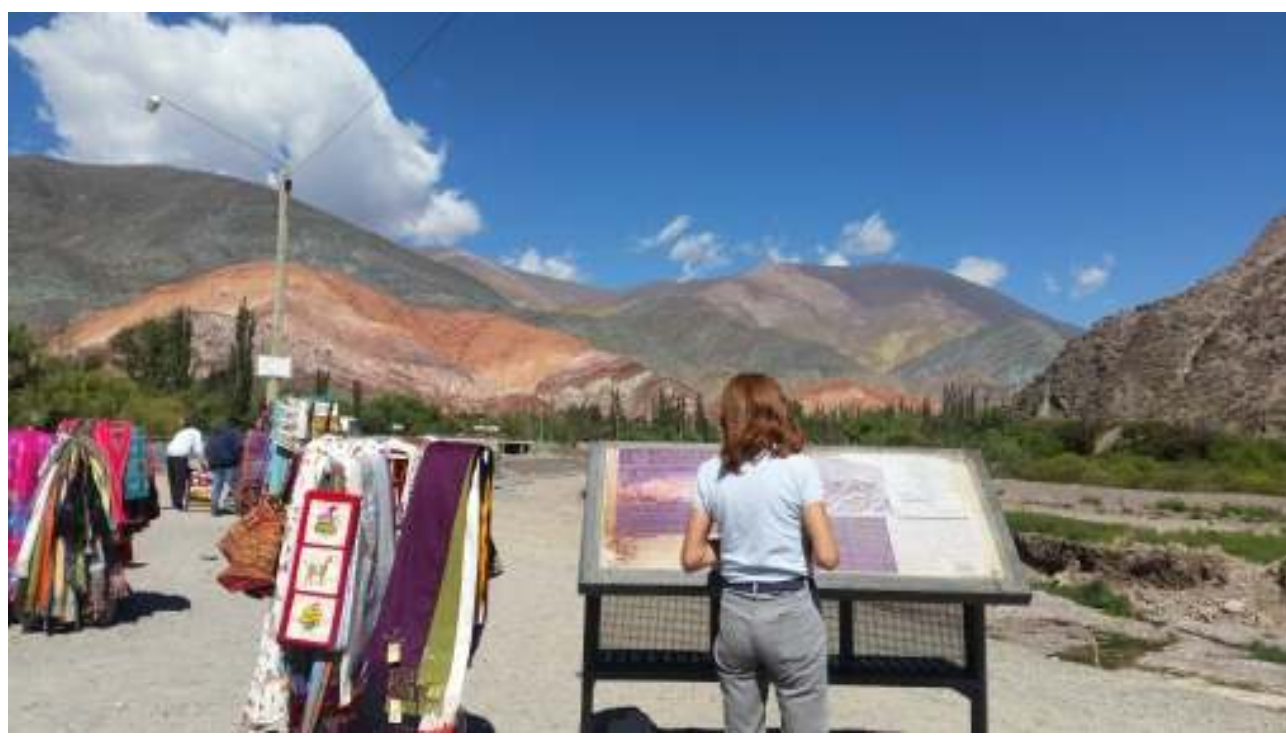

Fotografía: Claudia A. Troncoso (diciembre de 2016)

Punto de parada y observación de turistas a la entrada de Purmamarca. La cartelería diseñada por el gobierno de la provincia de Jujuy brinda información sobre la geologia del cerro de los Siete Colores que se obserba al fondo. Los turistas suelen obtener desde allí una de las imángenes más reproducidas del cerro.

Otro recorrido que invita a la reflexión es el paseo de Los Colorados también en Purmamarca, que comienza y termina en el pueblo luego de haber rodeado por detrás al Cerro de los Siete Colores. En este trayecto puede observarse una sucesión de formaciones rocosas coloridas y de formas inusuales que son producto de procesos erosivos. Este paseo vehicular y peatonal presenta ramificaciones desde el camino central compuesta por varios senderos improvisados para el tránsito a pie que acortan camino o que se dirigen hacia lugares elevados que han devenido puntos de observación espontáneos pero reiterados por los turistas. Estos puntos y los senderos son "indicados" por los trazos, las huellas que son actualizadas con el repetido tránsito de los visitantes a pie (ver figura 3). Pero también se comparten entre los turistas de varias formas, incluidas las alternativas de interacción que ofrecen actualmente algunos sitios web. Así una turista explica:

Tomamos otro camino, no me arrepiento. Al entrar al recorrido por el lado del cementerio de Purmamarca hay una bifurcación en el camino (el habitual es hacia el lado derecho) por confusión fuimos hacia la izquierda y nos encontramos con una gama de colores impresionantes y unas poblaciones de cardones aún mejores... al final el camino se corta y hay que volver...pero sin dudas valió la pena confundirse. (Tripadvisor, 2018) ${ }^{18}$ 


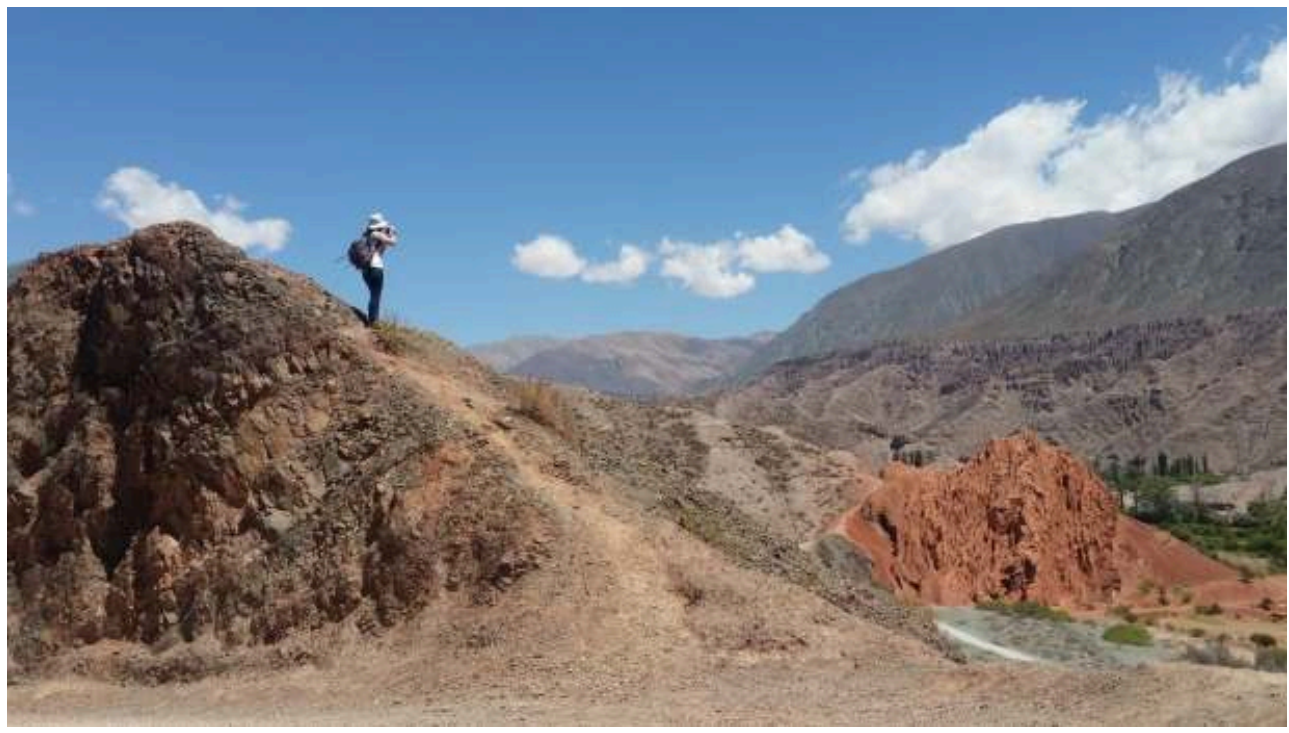

Fotografía: Claudia A. Troncoso (diciembre de 2016)

Paseo Los Colorados de Purmamarca. En las fotos uno de los senderos "fuera de ruta", es decir, fuera del trazado principal del paseo. Los turistas refuerzan recorridos improvisados para acceder a puntos de observación y de toma de fotografías.

Todos estos elementos orientan un movimiento que organiza espacial y temporalmente las formas de desplazamiento por el destino. En efecto, este transitar por la Quebrada no implica un movimiento continuo, parejo, ininterrumpido. Por el contrario, el movimiento y la pausa se combinan en un ritmo que con frecuencia puede ser pensado en términos de "coreografías" (Edensor, 2010) que involucran desplazamientos y puntos de encuentro colectivos marcados por cierta repetición. Estas maneras de recorrer el destino, junto con aquellas otras menos previstas, dan forma a una movilidad turística que reúne movimientos, representaciones y prácticas (Cresswell, 2010) en un proceso que define al destino turístico como tal.

Los viajes organizados con servicios que se repiten diariamente, las recomendaciones de guías turísticas y aquellas ofrecidas en oficinas de información al viajero, las sugerencias de turistas previos, todo esto contribuye en la definición de un recorrido, una dirección, un ritmo y ciertas formas de experimentar el desplazamiento turístico por la Quebrada que hablan, en cierta medida, de una práctica de desplazamiento compartida, reproducida, imitada pero también desafiada. En efecto, más allá de estas formas institucionalizadas, también se improvisan opciones que le imprimen orientaciones novedosas a estos movimientos iniciados por turistas curiosos que abren "caminos". Las líneas que diseña la práctica turística toman nuevos trazados que acompañan (y le dan forma a) las transformaciones generales del lugar. La ruta y otros caminos menores, sean estos transitados en vehículo o a pie, están involucrados en la formación y transformación de los ámbitos por los que se circula, en un proceso que puede dar lugar a alternativas respecto de aquellas formas institucionalizadas de desplazamiento. Y también, claro está, puede dar paso a la creación de nuevos negocios turísticos basados en "lo novedoso". Aquí es importante recordar que los recorridos "fuera de ruta" y el interés del turista de "ir donde los otros turistas no van" también ha dado lugar a negocios basados en estas formas de exclusividad. 


\section{La geografía turística lineal y móvil de la Quebrada de Humahuaca}

En su libro Lines. A brief history (2008) el antropólogo Tim Ingold, recurriendo a la línea como metáfora gráfica, propone comprender algunas prácticas de desplazamiento $\mathrm{y}$ distingue dos maneras en que este movimiento puede darse; ambas dibujan líneas de distinta naturaleza. Habla del wayfaring como forma de establecer recorridos que se adentran en determinados ámbitos geográficos de acuerdo con propósitos vinculados a la vida cotidiana, especialmente en sociedades no modernas. En este caso, se trata de líneas definidas conforme se va avanzando. En contraposición propone la idea de transport para caracterizar una forma de movimiento que atraviesa ámbitos geográficos (concebidos como superficies) con el propósito de alcanzar un destino identificado de antemano, trazando recorridos signados por la racionalidad y la eficiencia. Los medios de transporte modernos y las prácticas de desplazamientos que suelen asociarse a ellos, incluido el turismo, son pensados por Ingold a partir de estas formas de desplazamiento, como líneas que unen puntos predefinidos.

La idea de turismo asociada al transport es pertinente porque se trata de una práctica que se ha sumado a (y ha contribuido a la definición de) formas establecidas de recorrer el espacio propias de la modernidad, marcadas por la eficiencia y la racionalidad en el momento de unir dos o más puntos geográficos, aquel de origen del turista y aquel o aquellos de visita. En el mismo sentido, algunas formas de viaje turístico más institucionalizadas han generado propuestas donde el turista se encuentra aislado, desconectado de los espacios de tránsito y solo establece un vínculo con aquellos lugares identificados, en el contexto del viaje, como "destinos". En raras ocasiones, por otro lado, puede el turismo asociarse a la idea de wayfaring. Por más popular que sea en los tiempos actuales la idea del turismo "fuera de ruta", es decir, los intentos de asociar el viaje con motivos de ocio negando sus formas más o menos estandarizadas, es mucho menos frecuente el turismo que "hace camino al andar" que aquel que de una u otra manera, recurre a servicios creados en el mundo moderno para viajar con fines de ocio y recorre caminos ya andados.

41 Así y todo, sería prudente evitar asociar de manera directa el viaje turístico con la mera idea de "transporte de gente de un punto a otro", como traslado carente de significado, de actividad, en definitiva, de algún tipo de involucramiento por parte del turista en esa experiencia temporal y espacial que encara. $Y$ en este sentido, la idea de wayfaring también podría ser un punto de partida para analizar el desplazamiento turístico.

Los aspectos del viaje turístico en la Quebrada de Humahuaca invitan a pensar estas ideas en la medida en que este traslado, este transport del que habla Ingold, aun siendo un movimiento ya preestablecido sujeto a un servicio que "lleva" a los turistas como en los tours organizados, no deja de ser, de alguna manera, una ruta experimentada o vivenciada. De hecho, este traslado podría pensarse como una forma de movilidad turística densa, rica, plagada de aspectos sobre los cuales reflexionar e indagar.

Las rutas y los caminos se abren paso en terrenos que articulan materialidad y significados, sensaciones y discursos, historia y práctica contemporánea (Hvattum, Brenna, Elvebakk y Larsen, 2011:3). El recorrido por la Quebrada entrelaza todo esto, pero además, articula aspectos culturales, sociales, históricos, artísticos, estéticos y patrimoniales, que no son ajenos al turismo. El recorrido turístico invoca (y actualiza) 
una información variada y posibilidades concretas acerca de cómo transitar y experimentar este lugar. En efecto, este movimiento a través de la Quebrada ha sido "facilitado, imaginado y representado" (Hvattum, Brenna, Elvebakk y Larsen, 2011:2) por diferentes actores, en diferentes momentos y a través de diferentes prácticas; y entre ellas el turismo ha tenido un rol central. Complementariamente, los diferentes acondicionamientos para disfrutar turísticamente este lugar, para favorecer su visita y recorrido, también han alimentado y redefinido las maneras de imaginar y comprender la Quebrada como destino turístico.

En este sentido, la visita turística a la Quebrada podría ser pensada como una línea o conjunto de líneas que despliegan los turistas, que han sido consolidadas por la industria turística, estableciendo vínculos con otras prácticas de desplazamiento habilitadas por infraestructura, servicios, regulaciones y que se encuentra plagada de sugerencia acerca de cómo este lugar puede ser observado, interpretado, disfrutado. Movimiento, representación y práctica se conjugan para definir este lugar turístico como un lugar signado (como tantos otros) por formas específicas que toma la movilidad turística. Los recorridos, puntos de pausa y centros de estadía, junto con la existencia de servicios turísticos variados ofrecidos por diversos prestadores, consolidan formas de transitar la Quebrada, a la vez que organizan la visita al lugar. La presencia de ellos implica la existencia de selecciones y jerarquizaciones en la experiencia turística organizando qué hacer, dónde, cómo, cuándo y por cuánto tiempo; en definitiva organizando espacial y temporalmente la visita. En este sentido, las líneas desplegadas son pautadas y preestablecidas en el caso de los recorridos brindados por las excursiones comerciales y seguidos al pie de la letra por algunos de los turistas que se mueven por sus propios medios. Pero también hay lugar para el trazado de líneas que han sido más espontáneas cuando son llevadas adelante por aquellos turistas que se aventuran a definir nuevos senderos para conocer el destino. Si bien no podemos hablar plenamente de wayfaring en los términos de Ingold, sí hay un interés por ir más allá de lo institucionalmente propuesto que, en definitiva, podría dar pie a transformaciones en la forma de recorrer el destino.

Asimismo, aun las formas de recorrer el espacio más organizadas, previstas y establecidas a fuerza de repetición también pueden ser más que movimiento físico de personas de un lugar a otro. Esta forma de transitar define líneas con un movimiento cargado de historia, significados y prácticas, de modos de observar, de interpretar, de retratar (visual y verbalmente) el lugar que invitan a la reiteración pero también dan lugar a la reflexión acerca de la propia experiencia. Y evidentemente, pueden constituirse en dimensiones significativas (individuales o colectivas) del viajar.

Así, si bien cabe la posibilidad que estos tránsitos se experimenten con el tedio, la indiferencia, las ganas de llegar a destino (dicho sea de paso, actitudes y predisposiciones interesantes, a su vez, de investigar), también ofrecen otros aspectos que nos plantean el desafío de indagar la vitalidad de estos "tiempos muertos" y estas "extensiones sin interés". 


\section{BIBLIOGRAFÍA}

Armanini, José (1935). A Jujuy. Buenos Aires: Editorial ANLO.

Ballent, Anahí (2005). "Kilómetro 0: la construcción del universo simbólico del camino en la Argentina de los años treinta". Boletín del Instituto de Historia Argentina y Americana "Dr. Emilio Ravignani”, Tercera serie, n. 27, pp. 107-137.

Bertoncello, Rodolfo (2002). “Turismo y territorio. Otras prácticas, otras miradas”. Aportes y Transferencias, v. 6, n. 2, pp. 29-50.

Casanova, Eduardo (1936). "La Quebrada de Humahuaca". Historia de la Nación Argentina, citado en: Sánchez de Bustamante, Teodoro (1937). El camino a Bolivia por la Quebrada de Humahuaca. Contribución a su estudio. Buenos Aires: La Imprenta Mercatali.

Clarín (1991-1992 aprox.) “Fascículo Humahuaca 1". In: Clarín. Atlas Turístico. Buenos Aires: Clarín, 8 p.

Clarín-ACA (2010). “Salta y Jujuy. De Cafayate a Humahuaca”. In: Clarín-ACA. Libro de viajes de la Argentina. Buenos Aires: Arte Gráfico Editorial Argentino, v. 12, 32 p.

Cresswell, Tim (2010). “Towards a politics of mobility”. Environment and Planning D: Society and Space, v. 28, n. 1, pp. 17-31.

Crang, Mike (2006). "Circulation and emplacement the hollowed-out performance of tourism". In: Minca, Claudio; Oakes, Tim (eds.). Travels in paradox. Remapping tourism. Lanham: Rowman \& Littlefield, pp. 47-64.

Edensor, Tim (2010). "Walking in rhythms: place, regulation, style and the flow of experience". Visual Studies, v. 25, n. 1, pp. 69-79.

Edensor, Tim; Holloway, Julian (2008). "Rhythmanalysing the coach tour: the Ring of Kerry, Ireland”. Transactions of the Institute of British Geographers, v. 33, n. 4, p. 483-501.

Farías, Ignacio (2010). "Sightseeing Buses: Cruising, Timing and the Montage of Attractions". Mobilities, v. 5, n. 3, pp. 387-407.

Franklin, Adrian; Crang, Mike (2001). "The trouble with tourism and travel theory?". Tourist Studies, v. 1, n. 1, pp. 5-22.

Hvattum, Mari; Brenna, Brita; Elvebakk, Beate; Larsen, Janike (eds.) (2011). Routes, roads and landscapes. Surrey: Ashgate.

Ingold, Tim (2008). Lines. A brief history. Londres: Routledge.

Montagne, Víctor (1944). “La encantadora Quebrada de Humahuaca”. Revista Geográfica Americana, v. 9, n. 125, pp. 61-67.

Onfray, Michel (2016). Teoría del viaje. Poética de la geografía. Buenos Aires: Taurus.

Pueblos Andinos (2001) “Quebrada de Humahuaca”, julio-agosto. Revista elaborada por prestadores de servicios turísticos de Jujuy (Folheto).

Rauch, André (1995). “Les vacances et la nature revisitée (1830-1939)”. In: Corbin, Alain (dir.). L'avènement des loisirs (1850-1960). París: Aubier, pp. 108-153. 
Ritzer, George; Liska, Allan (2002). “'Mcdisneyization' and 'post-tourism': complementary perspectives on contemporary tourism”. In: Rojek, Chris; Urry, John (eds.). Touring cultures, Transformation of tourism and theory. Londres: Routledge, pp. 96-109.

Seca, Mirta (1989). “Introducción a la geografía histórica de la Quebrada de Humahuaca. Con especial referencia al pueblo de Tilcara”. Cuadernos de Investigación, n. 1, Instituto Interdisciplinario Tilcara, Facultad de Filosofía y Letras, UBA, Buenos Aires, 148 p.

Sheller, Mimi; Urry, John (2006). “The new mobilities paradigm”. Environment and Planning A, v. 38, n. 2, pp. 207-226.

Soto Avendaño, Ernesto (1930). Una vocación (confidencias de artista), Conferencia dada el 4 de marzo de 1929 en el Colegio de la Universidad Nacional de La Plata. La Plata: Talleres gráficos Olivieri y Domínguez.

Suárez Giambra, Liliana (2007). Huacalera. La "Finca Monterrey". Un lugar olvidado en la Quebrada de Humahuaca. Salta: Editorial Milor.

Toniol, Rodrigo (2011). “A caminhada como produtora de sentidos: uma etnografia das experiências de 'caminhadas na natureza' no âmbito de uma política pública”. Transporte y Territorio, n. 5, pp. 29-47.

Tripadvisor (2018). Disponible: <https://www.tripadvisor.com.ar/>, consulta: 12/9/2018.

Troncoso, Claudia (2012). Turismo y patrimonio en la Quebrada de Humahuaca. Lugares, actores y conflictos en la definición de un destino turístico argentino. Pasos Edita $\mathrm{N}^{\circ} 9$.

Troncoso, Claudia (2013). "Postales hechas realidad: la construcción de la mirada del turista y las imágenes que promocionan la Quebrada de Humahuaca”. In: Lois, Carla; Hollman, Verónica (eds.). Geografía y Cultura Visual. Los usos de las imágenes en las reflexiones sobre el espacio. Rosario: Prohistoria, pp. 221-248.

Vega, Carlos (1934). “Jujuy”. Revista Geográfica Americana, v. 2, n. 13, pp. 35-47.

Welcome Argentina (2018). Disponible: <https://www.welcomeargentina.com/>, consulta: $12 / 9 / 2018$.

Wyckoff, William; Dislaver, Larry (1997). "Promotional imagery of Glacier National Park". Geographical Review, v. 87, n. 1, pp. 1-26.

YPF (1998). Guía Turística YPF. Centro y noroeste. Santiago de Chile: YPF, 339 p.

YPF-ACA (2005). Argentina. Guía YPF de circuitos turísticos. Buenos Aires: YPF, 228 p.

Zillinger, Malin (2007). “Tourist Routes: A Time-Geographical Approach on German Car-Tourists in Sweden”. Tourism Geographies, v. 9, n. 1, pp. 64-83.

\section{NOTAS}

1. Con la difusión de las tecnologías de las comunicaciones que permitieron el acceso a información proveniente de cualquier rincón del planeta, la literatura especializada ha incorporado la discusión respecto de la posibilidad de viajar "sin moverse del lugar" (algunos aspectos de esta discusión pueden verse en Ritzer y Liska, 2002). Sin embargo, se asume que, al menos por el momento, el desplazamiento espacial continúa mediando esta práctica que llamamos turismo. 
2. Información de este tipo puede consultarse en los documentos de la Organización Mundial del Turismo (por ejemplo, los anuarios estadísticos), aunque también es la forma predominante de generar y organizar la información turística generada a nivel nacional.

3. Para una presentación de las ideas centrales de esta propuesta, véase Sheller y Urry (2006).

4. Onfray (2016), por ejemplo, presenta el tiempo de desplazamiento de la siguiente manera: "Flotando, vagamente unido a dos mojones, en un estado de ingravidez espacial y temporal, cultural y social, el viajero penetra en la tierra de nadie, como si abordase las costas de una isla singular" (41-42), una zona "blanca, neutra" (42). Por su parte, Rauch (1995: 132) recupera la forma en que estos espacios de circulación son presentados en guías turísticas donde se habla de los trayectos que vinculan lugares de interés como "vacíos" y "extensiones sin interés".

5. Esta ha sido una línea de trabajo que, con propuestas más tradicionales o más críticas, ha transitado frecuentemente la Geografía del turismo (Bertoncello, 2002).

6. El hotel de turismo de Tilcara fue inaugurado en 1962 y el de Humahuaca en 1973.

7. Efectivamente los movimientos de desplazamiento en la Quebrada exceden al turismo. Su cercanía con los pasos fronterizos hacia Bolivia y Chile hace de esta área una zona de desplazamientos comerciales internacionales intensos. Asimismo, la vida cotidiana de la población residente se desarrolla entre varias de las localidades quebradeñas y también incluye con frecuencia San Salvador de Jujuy (la distancia que separa Humahuaca de San Salvador de Jujuy se recorre en tres horas en trasporte público automotor; Purmamarca y Tilcara se encuentran aún más cerca de la capital provincial). Estas formas de desplazamiento también incluyen otros servicios y vehículos además de los mencionados: los servicios de remis son ampliamente utilizados para desplazamientos cotidianos y turísticos. La bicicleta también forma parte de los vehículos que se desplazan por la Quebrada para ambos tipos de desplazamientos. Es frecuente para algunos turistas también "hacer dedo" (autostop) como forma de desplazamiento de una localidad a otra.

8. A nivel nacional el turismo fue considerado como una política de estado con la sanción de la Ley Nacional de Turismo (№ 25.997 de 2005). Esto fue reforzado con la creación de herramientas de planificación (entre la que se destaca el Plan Federal Estratégico de Turismo Sustentable lanzado en 2005) y la jerarquización del organismo nacional dedicado al turismo (pasó de Secretaría a Ministerio en 2010).

9. El crecimiento de emprendimientos hoteleros y gastronómicos se desarrolló a partir de la década de 2000 de la mano del incremento en la llegada de turistas a la Quebrada. En general se trató de emprendimientos familiares realizados por emprendedores de origen nacional.

10. En años recientes la visita turística a la Quebrada suele incluir también la excursión al mirador de la intensamente promocionada serranía de Hornocal a $25 \mathrm{~km}$ de la localidad de Humahuaca.

11. Entre los científicos que han realizado trabajos en la zona se destacan los arqueólogos Juan Bautista Ambrosetti, Salvador Debenedetti, Eduardo Casanova, el antropólogo Fernando Márquez Miranda, los geógrafos Horacio Difrieri y Romualdo Ardissone, los folkloristas Augusto Raúl Cortázar y Salvador Canals Frau, entre otros. El conjunto de artistas incluye a José Terry, Pompeyo Boggio, Francisco Ramoneda, Ernesto Soto Avendaño, José Armanini y Medardo Pantoja.

12. El arqueólogo Eduardo Casanova participó de la reconstrucción del sitio arqueológico del Pucará de Tilcara a fines de la década de 1940 (que ya había sido excavado en 1908). José Armanini, pintor y escritor, fue uno de los fundadores, en 1961, de la Casa del Artista en Tilcara, entidad que nucleó a artistas y científicos que trabajaban en la zona.

13. Ernesto Soto Avendaño fue el escultor encargado de la construcción del Monumento a la Independencia en Humahuaca. La obra fue encargada al artista en 1934 e inaugurada en 1950.

14. En efecto, la mayoría de los turistas nacionales se acercan a algunas de las grandes ciudades del noroeste para luego dirigirse a la Quebrada. Este mismo camino lo realizan los turistas 
internacionales que ingresan al país por la ciudad de Buenos Aires. La excepción la constituyen los turistas internacionales que recorren Sudamérica iniciando el viaje de norte a sur.

15. Hay que tener en cuenta que la mayoría de los turistas nacionales que llegan a la Quebrada provienen de las grandes ciudades argentinas localizadas en ámbitos geográficos completamente diferentes a la Quebrada (no solo porque se trata de ámbitos urbanos sino también porque en general estas grandes ciudades se ubican en áreas relativamente llanas con un clima templado y húmedo).

16. Disponible en: < https://www.welcomeargentina.com/purmamarca/city-tourpurmamarca.html>.

17. Disponible en: < https://www.tripadvisor.com.ar/ShowUserReviews-g664067-d2530925r612931020-The_Hill_of_Seven_Colors-

Purmamarca_Province_of_Jujuy_Northern_Argentina.html\#>. Publicado: 05/09/2018.

18. Disponible en: < https://www.tripadvisor.com.ar/ShowUserReviews-g664067-d1651139r615158510-Paseo_de_los_Colorados-

Purmamarca_Province_of_Jujuy_Northern_Argentina.html>. Publicado: 9/9/2018.

\section{RESÚMENES}

Las formas de desplazamiento involucradas en el turismo constituyen un elemento central de esta práctica de ocio. Sin embargo, este es un aspecto poco abordado al momento de indagar los procesos de transformación de los destinos turísticos. Este artículo propone reflexionar acerca de la relación entre turismo y movilidad a partir del abordaje de un caso específico: la Quebrada de Humahuaca, histórico destino turístico en el noroeste de la Argentina.

o deslocamento é um elemento central da prática turística. Todavia, ele constitui um terreno pouco analisado no estudo dos processos de transformação dos destinos turísticos. O presente artigo procura refletir sobre a relação entre turismo e mobilidade a partir da análise de um caso específico: a Quebrada de Humahuaca, tradicional destino turístico no noroeste da Argentina.

Movement involved in tourism is essential to this leisure practice. However, it has been a nearly unexplored aspect in studies that analyze transformation in tourist destinations. The paper aims to discuss tourism in relation to mobility through a case study: Quebrada de Humahuaca, a traditional tourist destination in Northwestern Argentina.

tourism, mobility, Quebrada de Humahuaca

Le déplacement inhérent au tourisme est un élément central de cette pratique de loisir. Cependant, il s'agit d'un aspect à peine abordé par les études qui s'intéressent aux processus de transformation des destinations touristiques. Dans cet article on se propose de réfléchir sur la relation entre tourisme et mobilité a propos d'un cas spécifique : la Quebrada de Humahuaca, destination touristique historique du nord-ouest de l'Argentine. 
ÍNDICE

Palavras-chave: turismo, mobilidade, Quebrada de Humahuaca

Palabras claves: turismo, movilidad, Quebrada de Humahuaca

Índice cronológico: Siglo XX, comienzos del siglo XXI

Índice geográfico: Quebrada de Humahuaca, Argentina

Mots-clés: tourisme, mobilité, Quebrada de Humahuaca

\section{AUTOR}

\section{CLAUDIA ALEJANDRA TRONCOSO}

Doctora en Geografía

Investigadora del Consejo Nacional de Investigaciones Científicas y Técnicas (CONICET) y Profesora de la Universidad de Buenos Aires

claudia.a.troncoso@gmail.com 